\title{
Operational research applied to health services 2007 special issue
}

\author{
Franklin Dexter • Eric Marcon • Xiaolan Xie
}

Received: 4 February 2009 /Accepted: 5 February 2009/Published online: 21 February 2009

(C) Springer Science + Business Media, LLC 2009

The EURO Working Group on Operational Research Applied to Health Services was formed in 1975 as part of a programme for developing special interest groups within the European branch, EURO of the International Federation of Operational research Societies, IFORS. The group meets every year, each summer, for one week in a different host country, usually in Europe. Meetings are open to anyone with a quantitative background and an interest in the subject area. The objectives of the group are communication of ideas, knowledge and experience concerning the application of Operational Research (OR) approaches and methods to problems in the area of health services, mutual assistance among members, co-operation on joint projects as well as inspiration with regard to approaches and attitudes in this field.

ORAHS came back to France 27 years after ORAHS' 80 in Paris. Since then, French health systems have changed drastically and health care delivery engineering has attracted the interests of many academics. Many French

F. Dexter $(\bowtie)$

Department of Anesthesia, University of Iowa,

Iowa City, IA 52242, USA

e-mail: Franklin-Dexter@UIowa.edu

E. Marcon

LASPI, IUT de Roanne, Université Jean Monnet Saint-Étienne,

21 Avenue de Paris,

42334 Roanne Cedex, France

e-mail: marcon@univ-st-etienne.fr

X. Xie

Engineering and Health Division,

Ecole Nationale Supérieure des Mines de Saint-Etienne,

158 cours Fauriel,

42023 Saint-Etienne cedex 2, France

e-mail: xie@emse.fr hospitals have engaged in major re-engineering projects. The French speaking working group GISEH (Gestion et Ingénierie des SystEmes Hospitaliers) attracts over 192 members in management and engineering of healthcare systems. Since 2000, the region of Rhone-Alps has funded several major research programmes on health services engineering (HRP (2000-2003), HRP2 (2004-2006), HRP3 (2006-2009)). In Saint Etienne, the Ecole des Mines de Saint Etienne (ENSM.SE, one of the top engineering schools in France), the University of Jean Monnet (UJM) and the university hospital complex CHU-SE have created a joint research institute in health and health care.

ORAHS'2007 was sponsored by EURO, ROADEF, GDR-RO, and GDR-MACS. ORAHS'2007 was supported by the following French organisations, institutions and companies: ILOG, Cluster GOSPI, Région Rhône-Aples, Conseil Général de la Loire, Saint Etienne Métropole, Ville de Saint Etienne, Ministère de la recherche.

ORAHS'2007 offered a scientific program including six tutorial lectures, 8 invited plenary talks, and 102 technical presentations covering various aspects of health care delivery engineering. ORAHS'2007 introduced some innovations that, we hope, contribute to make ORAHS an international conference in a domain of increasing demands. Feature sessions were organized by several national/regional working groups on management and engineering of health care systems. A "Project Ideas" section included 10 min presentations highlighting challenges of health care delivery that would benefit from joint European and international research efforts. Tutorial talks of $2 \mathrm{~h}$ each by six experts were organized to give young researchers and health professionals a comprehensive view of healthcare delivery engineering.

This special issue contains eight papers selected from 20 submissions. The review process was handled by the three 
guest-editors. Each submitted paper was peer-reviewed by at least 2 reviewers and underwent at least two review rounds. The topics addressed are diverse.

The paper by Lavierie and Puterman addresses the nursing human resource planning. It proposes a linear programming model to estimate the number of nurses to train, promote to management and recruit over a 20 year planning horizon to achieve specified workforce levels. The model was developed to help policy makers plan a sustainable nursing workforce for British Columbia, Canada.

The next three papers address various issues related to surgery. Adan et al. consider the patient mix optimization and master surgery schedule generation for cardiothoracic surgery. They propose a mixed integer programming model taking into account stochastic length of stay. The results show that a better performance on target utilization levels of resources can be achieved by considering the stochastic length of stay. Marjama et al. use simulation to compare different workflow models in operating rooms. All parallel work-flow models demonstrated better cost-efficiency than the traditionally sequenced working pattern. Staffing costs per case were $7 \%$ lower in the best induction model than in the traditional model. Lehtonen et al. study the connection between coronary artery bypass graft $(\mathrm{CABG})$ operation time and quality. This study shows that there is not a connection between CABG operation times and health related quality of life (HRQoL). Likewise, the speed of the surgeon does not influence improvement in HRQoL.

Two papers address the design and optimization of patient flows and material flows. Villa et al. describe three hospital redesign projects to show how to centre patient flow logistics around the patient care needs. Augusto and Xie address a pharmacy delivery design problem. A mixed integer programming-based approach is used to design the pharmacy pickup and delivery routes for transporters, better balancing the workload of pharmacy personnel. This approach is combined with a simulation model to redesign the delivery process of the pharmacy department of a French university teaching hospital.

The last two papers address different oncology related issues. Chahed et al. explores operational research opportunities within the home care context. The literature on investigations dealing with operation planning within the area of home care management is reviewed. Different models for chemotherapy at home are presented and analyzed. Langabeer and Ozcan addresses the issue of scale economy of oncology care. Data envelopment analysis and a longitudinal Malmquist index over a 5-year period were applied to specialized inpatient cancer centers to determine if these specialized centers achieve higher productivity over time and if scale leads to higher operating efficiency. Results show that oncology care has not benefited from increasing returns to scale.

We would like first to thank Yasar A. Ozcan to make this special issue possible. We are also grateful to reviewers for their timely and quality review reports that allowed us to ensure the high standard of papers accepted in this special issue: Armand Baboli, Jonathan Bard, Beatrix Besombes, John Blake, Sally Brailsford, Vanda De Angelis, Nico Dellaert, Maria Di Mascolo, Dan France, Alexia Gouin, Frédéric Grimaud, Alain Guinet, Jean Pierre Grandhaye, Michel Gourgand, Erwin Hans, Zhibin Jiang, Saïd Kharraja, Mehdi Lamiri, Mark Lawley, Danielle Masursky, Andrea Matta, Nadine Meskens, Stefan Nickel, Liam O’Neill, Christophe Pascal, Marion Rauner, Warren Sandberg, Arjan Shahani, Angela Testi, Lorraine Trilling, Jan Vissers, Brian Williams and Peter Williams. 